\title{
Correction of profiles of in-situ chlorophyll fluorometry for the contribution of fluorescence originating from non-algal matter
}

\author{
Xiaogang Xing, ${ }^{* 1,2}$ Hervé Claustre ${ }^{3}$ Emmanuel Boss, ${ }^{4}$ Collin Roesler, ${ }^{5}$ Emanuele Organelli, ${ }^{3,6}$ \\ Antoine Poteau, ${ }^{3}$ Marie Barbieux, ${ }^{3}$ Fabrizio D'Ortenzio ${ }^{3}$ \\ ${ }^{1}$ State Key Laboratory of Satellite Ocean Environment Dynamics, Second Institute of Oceanography, State Oceanic \\ Administration, Hangzhou, China \\ ${ }^{2}$ Takuvik Joint International Laboratory and Québec-Océan, Université Laval, Québec, Québec, Canada \\ ${ }^{3}$ Laboratoire d'Océanographie de Villefranche (LOV), Sorbonne Universités, UPMC Univ Paris 06, CNRS, UMR 7093, \\ Villefranche-sur-mer, France \\ ${ }^{4}$ School of Marine Sciences, University of Maine, Orono, Maine \\ ${ }^{5}$ Department of Earth and Oceanographic Science, Bowdoin College, Brunswick, Maine \\ ${ }^{6}$ Plymouth Marine Laboratory, Prospect Place, The Hoe, Plymouth, UK
}

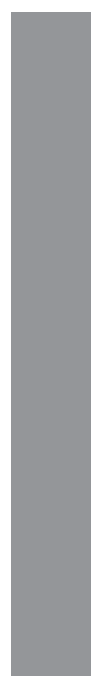

\begin{abstract}
In situ chlorophyll fluorometers have been widely employed for more than half a century, and to date, it still remains the most used instrument to estimate chlorophyll-a concentration in the field, especially for measurements onboard autonomous observation platforms, e.g., Bio-Argo floats and gliders. However, in deep waters (> $300 \mathrm{~m}$ ) of some specific regions, e.g., subtropical gyres and the Black Sea, the chlorophyll fluorescence profiles frequently reveal "deep sea red fluorescence" features. In line with previous studies and through the analysis of a large data set (cruise transect in the South East Pacific and data acquired by 82 BioArgo floats), we show that the fluorescence signal measured by a humic-like DOM fluorometer is highly correlated to the "deep sea red fluorescence." Both fluorescence signals are indeed linearly related in deep waters. To remove the contribution of non-algal organic matter from chlorophyll fluorescence profiles, we introduce a new correction. Rather that removing a constant value (generally the deepest chlorophyll a fluorescence value from the profile, i.e., so-called "deep-offset correction"), we propose a correction method which relies on DOM fluorometry and on its variation with depth. This new method is validated with chlorophyll concentration extracted from water samples and further applied on the Bio-Argo float data set. More generally, we discuss the potential of the proposed method to become a standard and routine procedure in quality-control and correction of chlorophyll a fluorescence originating from Bio-Argo network.
\end{abstract}

\section{Introduction and motivation}

In situ chlorophyll fluorometers have provided a simple, fast, and effective method for estimating chlorophyll-a concentration since the 1960s (Lorenzen 1966). Thanks to recent technological advances, in situ fluorometers are small (about $15 \mathrm{~cm}$ length and $6 \mathrm{~cm}$ diameter), have low power consumption (typically $<300 \mathrm{~mW}$ ), measure at high frequency (about $1 \mathrm{~Hz}$ ) and are relatively cheap. They have contributed significantly to our current understanding on the spatio-temporal dynamics of phytoplankton (Cullen 1982; Boss and Behrenfeld 2010). To date, they have been integrated to every oceanographic research platform such as CTD rosettes (Cullen 1982), flow-through systems (Platt 1972), moored buoys (Kinkade et al. 1999; Pettigrew and Roesler 2005), BioArgo floats (Boss et al. 2008; Mignot et al. 2014; Xing et al.

*Correspondence: xing@sio.org.cn
2014), gliders (Niewiadomska et al. 2008; Sackmann et al. 2008; Cetinić et al. 2009), and even elephant seals (Blain et al. 2013; Guinet et al. 2013).

However, understanding the significance of the signal produced by fluorometers has challenged the community since its early days (e.g., Cullen 1982; Falkowski and Kiefer 1985). On the one hand, the in vivo chlorophyll fluorescence signal is affected by sources of variability such as phytoplankton photo-physiology, nutrient status and species composition (Cullen 1982; Geider et al 1998; Proctor and Roesler 2010; MacIntyre et al. 2011). On the other hand, it can also be contaminated by other fluorescent sources such as detrital pigment (Marra and Langdon 1993) and colored dissolved organic matter (Proctor and Roesler 2010; Röttgers and Koch 2012). Separating these two sources (phytoplankton related from contamination with non-phytoplankton sources) is often difficult. 
South East Pacific $\left(33.04^{\circ} \mathrm{S} 81.08^{\circ} \mathrm{W}\right)$

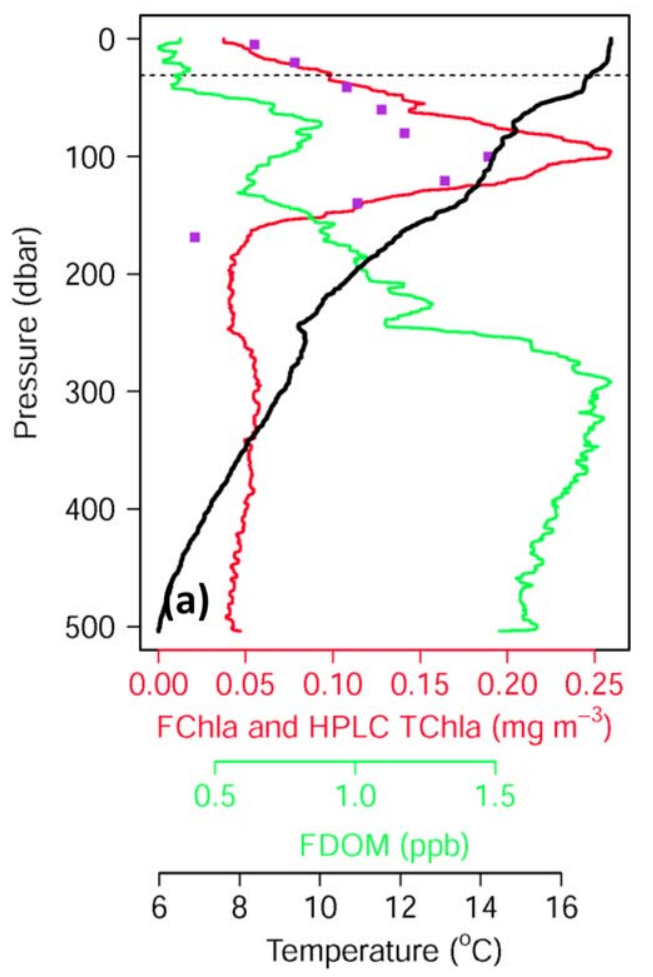

Black Sea $\left(43.28^{\circ} \mathrm{N} 30.89^{\circ} \mathrm{E}\right)$

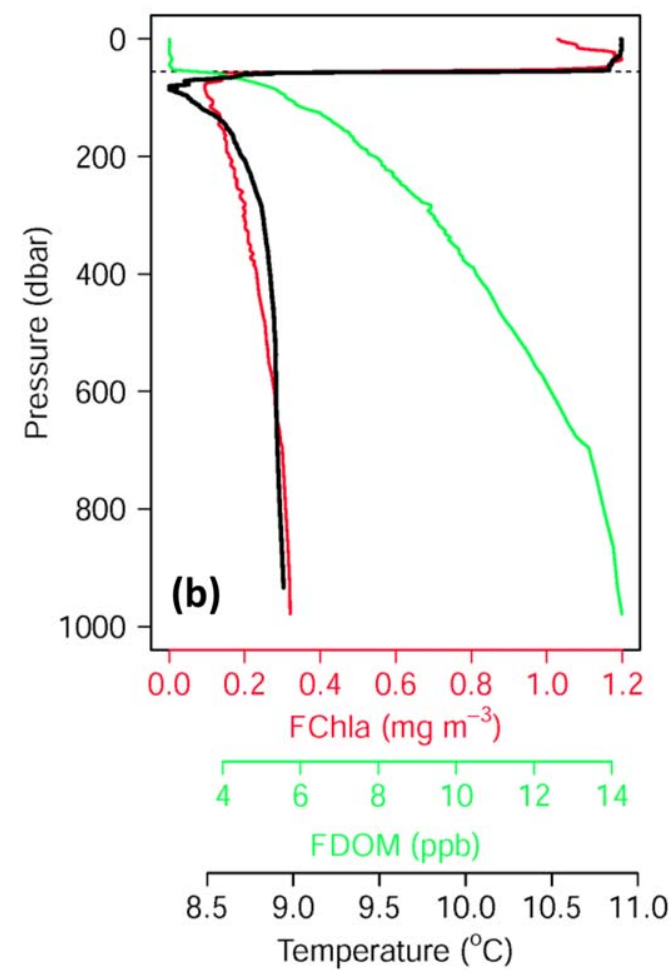

Fig. 1. Two examples of the "deep non-zero issue" of chlorophyll fluorometry, observed in (a) the South East Pacific during the BIOSOPE cruise (station St19-CTD187, 3 December 2004) and (b) by a Bio-Argo float WMO 6900807 deployed in the Black Sea (profile No. 001, 5 December 2014). The purple points represent the chlorophyll-a concentration determined by HPLC analysis. The black dashed lines represent the mixed layer depth (MLD).

Calibrated fluorometers sometimes measure non-zero values at depths where the presence of significant concentrations of phytoplankton is not expected. Previously, the non-zero deep values were considered to be due to a bias resulting from factory calibration as this was established for the sensor alone and not for the sensor mounted on the platform used for its deployment. This bias was thus simply corrected through subtracting a fixed value from the whole fluorescence profile (Schmechtig et al. 2014), generally the deepest value from the profile (e.g., Xing et al. 2011, 2014; Guinet et al. 2013). However, such dark current correction often meets a problem in some regions (e.g., some sub-tropical areas, the Arabian Sea), where the fluorescence signals display unexpected variations with depth in waters deeper than $300 \mathrm{~m}$ (Broenkow et al. 1983; Lewitus and Broenkow 1985; Breves et al. 2003; Claustre et al. 2008), i.e., the so-called "deep sea red fluorescence." Figure 1 illustrates this issue in the South East Pacific (Fig. 1a) and Black Sea (Fig. 1b). The South East Pacific profile has a "curve" shape from 200 to $500 \mathrm{~m}$. The profile in the Black Sea increases monotonically with depth from 70 to $1000 \mathrm{~m}$. There is no doubt that for both profiles the deepoffset correction does not work, as it leads to non-zero chlorophyll values in deep waters.
The laboratory experiments and field validation of Proctor and Roesler (2010), as well as the field observations by Röttgers and Koch (2012), suggest that the fluorescent dissolved organic matter (FDOM) could contribute significantly to the signal measured by chlorophyll fluorometers. It should be noted that, the FDOM observation includes not only the dissolved organic matter, but also fluorescent nonalgal particles. Although the more accurate definition should be the fluorescent colored detrital matter, we denote it here as FDOM. Given that DOM fluorometers are often deployed side-by-side with chlorophyll fluorometers, we propose here a simple method to correct in situ chlorophyll fluorescence measurements at depth. Its performance is validated with data collected during the BIOSOPE cruise (Claustre et al. 2008) in the South East Pacific and is applied to Bio-Argo floats deployed in diverse environments.

\section{Materials and procedures}

Instruments and data

We use two datasets to evaluate the method proposed below. The first dataset, used for validation of the method, is that of the "BIOSOPE" biogeochemical cruise, carried out in 

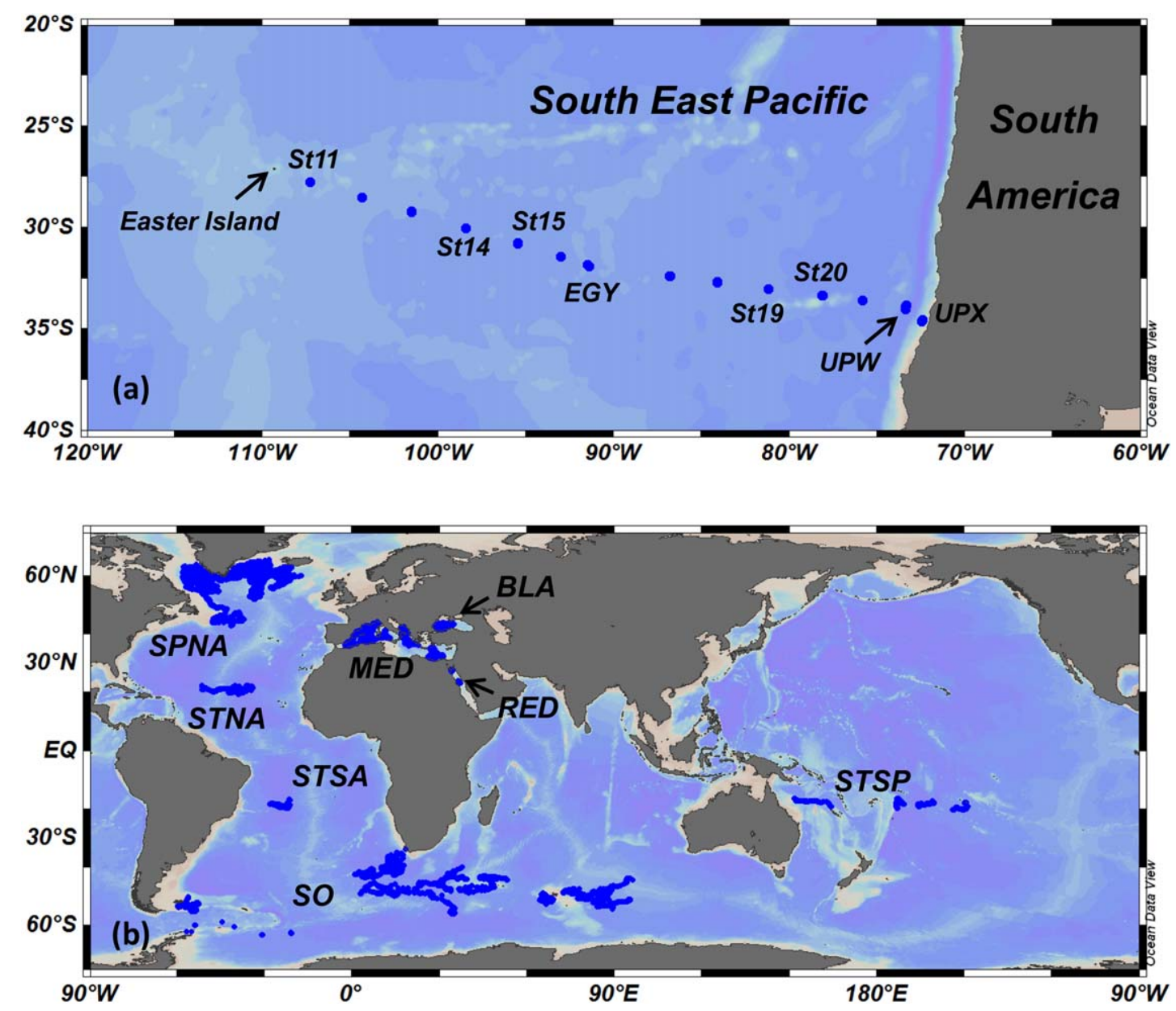

Fig. 2. (a) station map of the Leg 2 of BIOSOPE cruise in the South East Pacific, and (b) profile position map of 82 Bio-Argo floats that are deployed in diverse global waters such as: Black Sea ("BLA"), Red Sea ("RED"), Mediterranean Sea ("MED"), subpolar North Atlantic ("SPNA"), subtropical North Atlantic ("STNA"), subtropical South Atlantic ("STSA"), subtropical South Pacific ("STSP"), and the Atlantic and Indian sectors of the Southern Ocean ("SO").

the South East Pacific Ocean during the austral summer of 2004 (Claustre et al. 2008). In this study, only data collected during Leg 2 (from the center of sub-tropical gyre to the upwelling area off Chile) are utilized (Fig. 2a), as a DOM fluorometer was not available during Leg 1. Chlorophyll fluorescence (FChla) were obtained in situ using a Chelsea Aquatracka III Chlorophyll fluorometer with excitation wavelength at $430 \mathrm{~nm}$ and emission wavelength at $685 \mathrm{~nm}$ (bandwidth $30 \mathrm{~nm}$ ), and fluorescent dissolved organic matter (FDOM) were measured with a Wetlabs Wetstar DOM fluorometer with excitation wavelength at $370 \mathrm{~nm}$ and emission wavelength at $460 \mathrm{~nm}$ which measures the fluorescence of humic-like CDOM (Coble 1996, 2007; Nelson and Gauglitz 2016). This cruise provided discrete profiles of chlorophyll-a concentration determined by High-performance liquid chromatography (HPLC) analysis ( $~ 10$ samples per profile) (Ras et al. 2008) allowing a validation of the proposed correction method.
The second dataset, used to showcase the application of the method, is a Bio-Argo database that includes data from 82 Provor CTS-4 floats designed by the NKE Instrumentation Inc. (Organelli et al. 2016). These floats had been deployed in diverse waters such as: Black Sea (2), Red Sea (2), Mediterranean Sea (30), subpolar North Atlantic (19), subtropical regions (12) (in the North Atlantic (4), South Atlantic (3), and South Pacific (5), respectively), and the Atlantic and Indian sectors of the Southern Ocean (17). All were equipped with a SeaBird CTD and a WETLabs ECO triplet sensor that includes a chlorophyll fluorometer with excitation wavelength at $470 \mathrm{~nm}$ and emission wavelength at $695 \mathrm{~nm}$, a DOM fluorometer with excitation wavelength at $370 \mathrm{~nm}$ and emission wavelength at $460 \mathrm{~nm}$, and a backscattering sensor at $700 \mathrm{~nm}$.

\section{Method}

Our method is based on the calibration method of chlorophyll fluorometer proposed by Proctor and Roesler (2010). 
They also addressed the temperature effect on the variability of dark currents of fluorometers in addition to the contribution of FDOM. It was attributed to the well-known characteristic of LEDs that emit more light in colder temperature (Mroczka 1988). However, recently built fluorometers and scattering sensors do not exhibit this temperature effect (Cetinić et al. 2009; Sullivan et al. 2013; C. Roesler unpubl.). Therefore, in this study, the temperature effect is ignored and the method of Proctor and Roesler (2010) is modified as follows:

$$
\begin{gathered}
\mathrm{DC}_{\mathrm{cor}}=\mathrm{DC}_{\text {meas }}-\mathrm{DC}_{\mathrm{dark}}-\mathrm{DC}_{\mathrm{FDOM}} \\
\mathrm{DC}_{\mathrm{FDOM}}=\left(\mathrm{DC}_{\mathrm{FDOMmeas}}-\mathrm{DC}_{\mathrm{FDOMdark}}\right) * \text { Slope }_{\mathrm{FDOM}}
\end{gathered}
$$

Here $\mathrm{DC}_{\mathrm{cor}}$ represents the corrected chlorophyll fluorescence. $\mathrm{DC}_{\text {meas, }}$ DC $\mathrm{C}_{\text {dark, }}$ and $\mathrm{DC}_{\mathrm{FDOM}}$ represent the measured chlorophyll-a fluorescence (hereafter called as FChla), dark current (assumed constant) and the bias due to FDOM interference, respectively. The measurements of FDOM with a DOM fluorometer are assumed to be proportional to the measurable signal with the Chla fluorometer that originated from FDOM not from in vivo phytoplankton. $\mathrm{DC}_{\mathrm{FDOMmeas}}$ and DC $_{\text {FDOMdark }}$ represent measured FDOM and its dark cur-

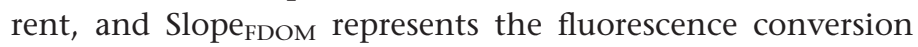
factor from FDOM measured with a DOM fluorometer to FDOM measured with a chlorophyll fluorometer. Except for Slope $_{\text {FDOM, }}$ all variables in Eqs. 1 and 2 are in digital counts or voltage (depending on the sensor output type). We further replaced all the values in counts/volts with their converted values in engineering units (using the manufacturer calibration), combining the two equations above:

$$
\begin{aligned}
& \text { FChla }_{\text {cor }}=\mathrm{FChla}_{\text {meas }}-\mathrm{FChla}_{\mathrm{dark}}-\text { Slope }_{\mathrm{FDOM}} \\
& \quad *\left(\mathrm{FDOM}_{\text {meas }}-\mathrm{FDOM}_{\mathrm{dark}}\right)
\end{aligned}
$$

Or written as:

$$
\begin{gathered}
\text { FChla }_{\mathrm{cor}}=\text { FChla }_{\text {meas }}-\text { Slope }_{\mathrm{FDOM}} * \mathrm{FDOM}_{\text {meas }}-\mathrm{C} \\
\text { C }=\text { FChla }_{\text {dark }}-\text { Slope }_{\mathrm{FDOM}} * \text { FDOM }_{\text {dark }}
\end{gathered}
$$

Here FChla and FDOM are in units of $\mathrm{mg} \mathrm{m}^{-3}$ and $\mathrm{ppb}$, respectively. Slope $\mathrm{FDOM}_{\mathrm{M}}$ is in units of $\mathrm{mg} \mathrm{m}^{-3} \mathrm{ppb}^{-1}$. FChladark and FDOM $_{\text {dark }}$ represent the departure of the factorycalibration blank from the blank value in the field for the two fluorometers, respectively.

Proctor and Roesler (2010) suggested that the dark current calibration of chlorophyll fluorometers should be conducted before in-situ measurements and on the platform it is deployed on. Such procedures, however, cannot always be performed. Our method, in addition to correcting for contamination by FDOM also provides an estimate of the dark current.

If we assume that the FDOM conversion coefficient (Slope $_{\text {FDOM }}$ ) is uniform for the whole water column (i.e., that the amount of contamination of the chlorophyll fluorometer is linearly dependent on the FDOM similarly at all depth; see fig. 4 in Proctor and Roesler [2010]), and choose an appropriate depth range (e.g., 400 to $1000 \mathrm{~m}$ ) where the chlorophyll concentration can be assumed to be zero (i.e., FChla $_{\text {cor }}=0$ ), then, at those depths, Eq. $3 \mathrm{~b}$ would provide the constant value for $\mathrm{C}$, and Eq. 3a would become a simple linear equation:

$$
\mathrm{FChla}_{\text {meas }}=\text { Slope }_{\mathrm{FDOM}} * \mathrm{FDOM}_{\text {meas }}+\mathrm{C}
$$

Applying a linear regression analysis $\left(\mathrm{FChla}_{\text {meas }} \sim \mathrm{FDOM}_{\text {meas }}\right)$, Slope $_{\text {FDOM }}$ and $\mathrm{C}$ are determined and can then be used to correct the whole FChla profile (Eq. 3a). In other words, this correction is extrapolated to the surface where the separation of FDOM contribution from chlorophyll fluorescence signal is, otherwise, unfeasible.

The method proposed is hereafter referred to as the FDOM-based method. To test this correction, we compare it with the classical "deep-offset correction" where the minimum FChla at depth for each profile is chosen as the constant dark current value to be subtracted from the whole FChla profile (Schmechtig et al. 2014). In other words, the deep-offset correction is based on an assumption that the non-zero FChla values in deep waters derive from a factorycalibration error in the dark current of the fluorometer or from a drift of this dark current.

Here, the statistical parameter RMSE (root mean square error) is used to quantify the effectiveness of the method, defined as:

$$
\mathrm{RMSE}=\sqrt{\frac{\sum_{\mathrm{n}=1}^{\mathrm{N}}\left(\mathrm{A}_{\mathrm{n}}-\mathrm{P}_{\mathrm{n}}\right)^{2}}{\mathrm{~N}}}
$$

Here $A_{n}$ is the actual value, and $P_{n}$ is the predicted value. RMSE represents the absolute deviation with the same units as $A_{n}$ and $P_{n}, N$ represents the number of samples. In this study, $A_{n}$ represents the total chlorophyll-a concentration determined by HPLC analysis, which is regarded as the most accurate measurement of chlorophyll-a concentration to date. $P_{n}$ represents the corrected [Chla] with either one of the two correction methods.

\section{Procedures}

For the FDOM-based correction method, it is essential to identify the depth range where the linear regression analysis is applied, i.e., where the actual chlorophyll fluorescence is assumed to be zero a priori. The maximum depth is defined as the maximum observation depth: 500 and $1000 \mathrm{~m}$ for the BIOSOPE and Bio-Argo float data, respectively. The minimum depth, hereafter called "TopDepth," needs to be determined a priori. In this study, its determination is based on the depth where FChla reaches its "apparent minimum,"

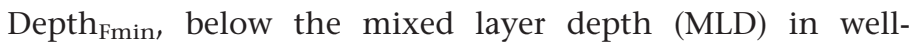
mixed waters or below the deep chlorophyll-a maximum in stratified waters. However, some profiles show an apparent 


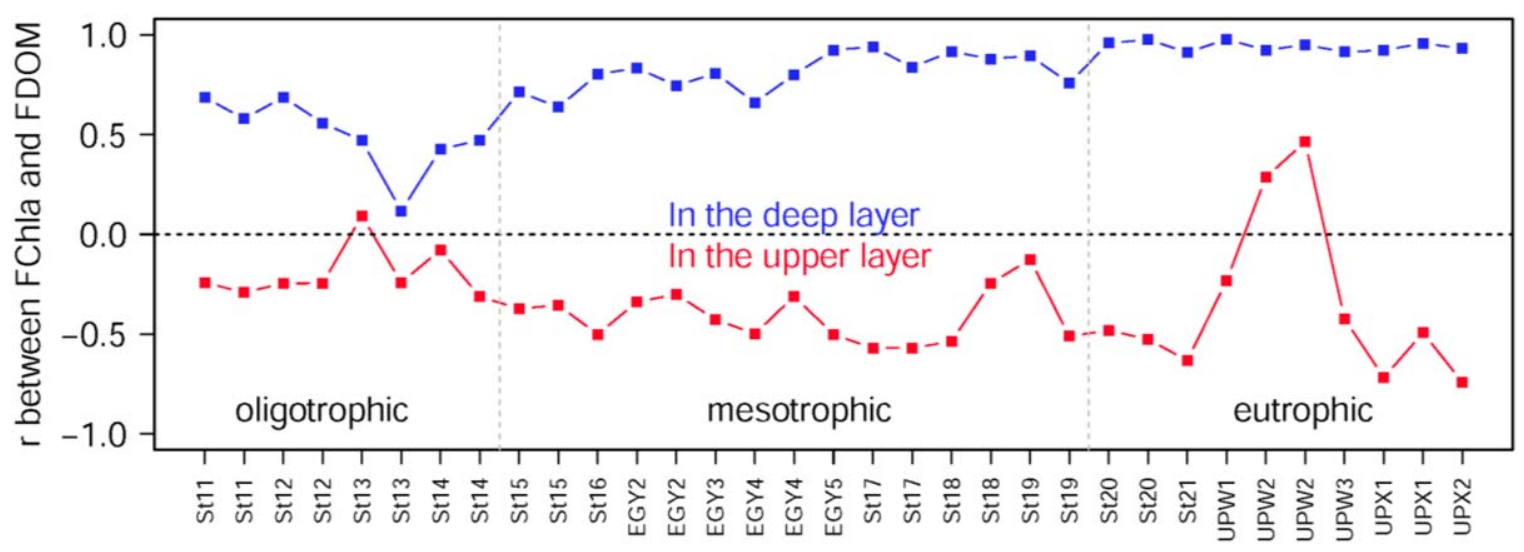

Fig. 3. Variations along the BIOSOPE longitudinal transect in the South East Pacific of correlation coefficient ( $r$ ) between FChla and FDOM. The deep

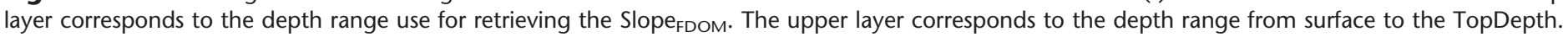

minimum deeper than $400 \mathrm{~m}$ (e.g., Fig. 1a). In such situations, the linear regression is applied from $400 \mathrm{~m}$ or from one hundred meter deeper than the MLD, depending on which depth is larger (see Eq. 6). MLD is here determined as the depth where a density change from sea surface (at $10 \mathrm{~m}$ ) reaches $0.125 \mathrm{~kg} \mathrm{~m}^{-3}$ (Monterey and Levitus 1997). Therefore, the TopDepth is determined as follows:

$$
\begin{gathered}
\text { TopDepth }=\text { Depth }_{\text {Fmin }} \quad \text { Depth } \\
\text { Fmin } \\
\text { TopDepth }=\max (400,(\mathrm{MLD}+100)) \text { Depth }_{\text {Fmin }}>400
\end{gathered}
$$

The correction procedures involves three steps: (1) determining the depth range for regression analysis, (2) applying a linear regression analysis between FChla and FDOM within the depth range, and (3) applying the regressed parameter to Eq. $3 \mathrm{a}$ in the whole profile, to retrieve the corrected FChla profile. It is noteworthy that, in practical application, there are some regions (like subpolar North Atlantic) where there is little change of FChla and FDOM in deep waters. In such cases the linear regression sometimes results in a negative Slope $_{\text {FDOM. }}$ However, since the interference of FDOM on chlorophyll fluorometer is only expected to add to the signal, a negative Slope FDOM $_{\text {is }}$ deemed unphysical. Thus, in

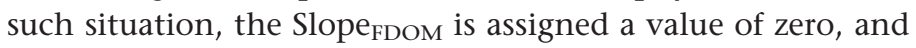
the corresponding constant $(\mathrm{C})$ become the median value of the lowest ten values.

\section{Assessment}

\section{Deep non-zero apparent FChla and its correlation with FDOM}

The profile shown as an example in Fig. 1a was observed in the eastern border of the South Pacific subtropical gyre. The FChla profile displays a curved shape below $200 \mathrm{~m}$. Below the deep chlorophyll maximum (DCM), FChla decreases with depth, reaching a minimum at around $210 \mathrm{~m}$. Below this minimum, the fluorescence signal increases reaching a local minimum at a depth of $300 \mathrm{~m}$ and then decreases again. Compared with the chlorophyll values determined at nine discrete depths by HPLC, total chlorophyll-a concentration is similar to that measured by in vivo chlorophyll fluorescence, with the DCM located at the same depth $(100 \mathrm{~m})$. At $160 \mathrm{~m}$, HPLC chlorophyll decreases to $0.02 \mathrm{mg}$ $\mathrm{m}^{-3}$ and it is expected to decrease continuously with depth until reaching very close to zero. At this station the HPLC measurement cannot be used to examine the profile below $200 \mathrm{~m}$. However, the FDOM signal shows a similar shape to FChla in deep waters with one peak just above the DCM depth and a relative maximum around $300 \mathrm{~m}$ (Fig. 1a). Below $300 \mathrm{~m}$, the two fluorescence signals tightly covary over the vertical, supporting our assumption that FDOM contributes to FChla. The correlation coefficient $(r)$ between FDOM and FChla reaches 0.76 in the TopDepth $(\sim 200 \mathrm{~m})-500 \mathrm{~m}$ layer, while it is -0.51 in the surface-TopDepth layer.

For all other BIOSOPE stations, measured FChla and FDOM in deep waters are well correlated with correlation coefficients $>0.55$ (except for four profiles in St13 and St14), with an average value of 0.78 (Fig. 3). Specifically, the correlation at depth is found highest in the 10 eutrophic stations in the vicinity of upwelling area (St20-UPX2, $r=0.94)$; it becomes lower in the mesotrophic waters (St15-St19, $r=0.81$ ); and their correlation is lowest in the oligotrophic waters (St11-St14, $r=0.50$ ). On the contrary, FChla and FDOM are quite weakly correlated in the upper layer, generally negatively and sometimes positively (average value as -0.41). This suggests both fluorescence signals have the same source of signal in deep waters while different sources for signal dominating their variability near the surface. Based on the laboratory and in situ observations (Proctor and Roesler 2010; Röttgers and Koch 2012), we assign the cause of correlation to FDOM contributing to FChla at depth. Such effect is not obvious within the euphotic layer where the chlorophyll dominates FChla, while FDOM concentration 

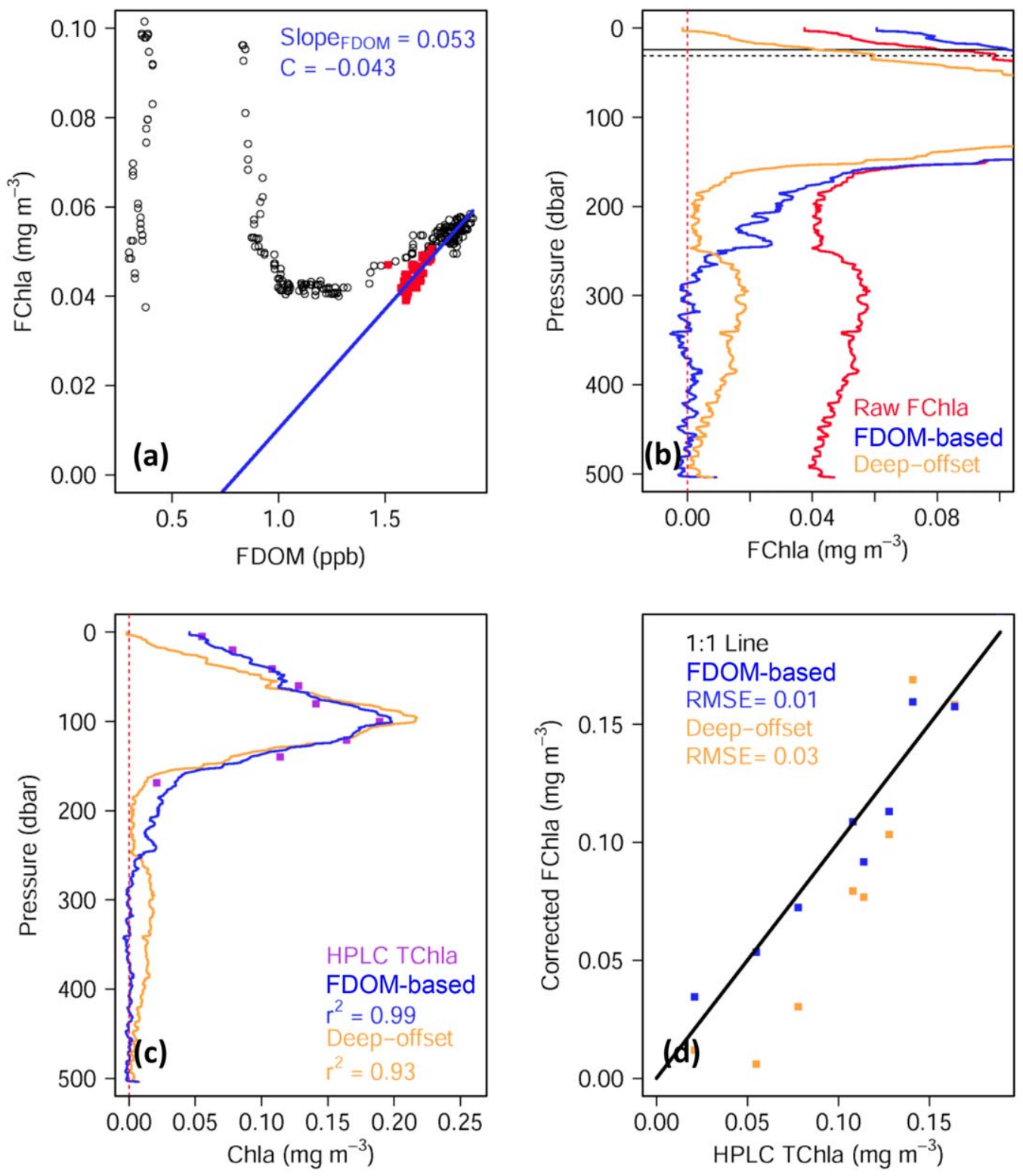

Fig. 4. Example of the FDOM-based method and its comparison with deep-offset correction, for the South East Pacific profile presented in Fig. 1a. (a) Scatter plot between FDOM and FChla, with red points represent the points for the linear regression analysis over the depth range from 400 to $500 \mathrm{~m}$. (b) Dark corrected profiles by two methods. (c) Vertical profile of FChla corrected by two methods with HPLC data superimposed. (d) Scatter plot between two corrected chlorophyll-a concentration and HPLC TChla, the black line represents the $1: 1$ line.

and corresponding fluorescence is lower than at depth due, most likely, to photo-oxidation (Vodacek et al. 1997). With increasing depth, chlorophyll concentration tends to very low and FDOM concentration increase. Consequently, FDOM's contribution to FChla increases with depth, resulting in a chlorophyll fluorescence shape in deep waters that is similar to that of FDOM.

\section{Validation of the method with HPLC}

Following the method proposed above, the Slope ${ }_{\mathrm{FDOM}}$ and $\mathrm{C}$ are obtained based on a simple linear regression
(Eq. 4), and then applied to the whole apparent FChla profile to remove the contribution of FDOM and retrieve the corrected FChla. The HPLC total chlorophyll observations are used to validate the FDOM-based correction method and to compare it with the deep-offset correction (e.g., Fig. 4b). We find that the FDOM-based method works better than the other one when compared to the HPLC data. The linear correlation to HPLC improves from $r=0.93$ to $r=0.99$ (Fig. 4c). The change in the shape of the deep profile with FDOMbased correction is very significant although not directly validated (Fig. 4b). The deep-offset correction is incapable of 

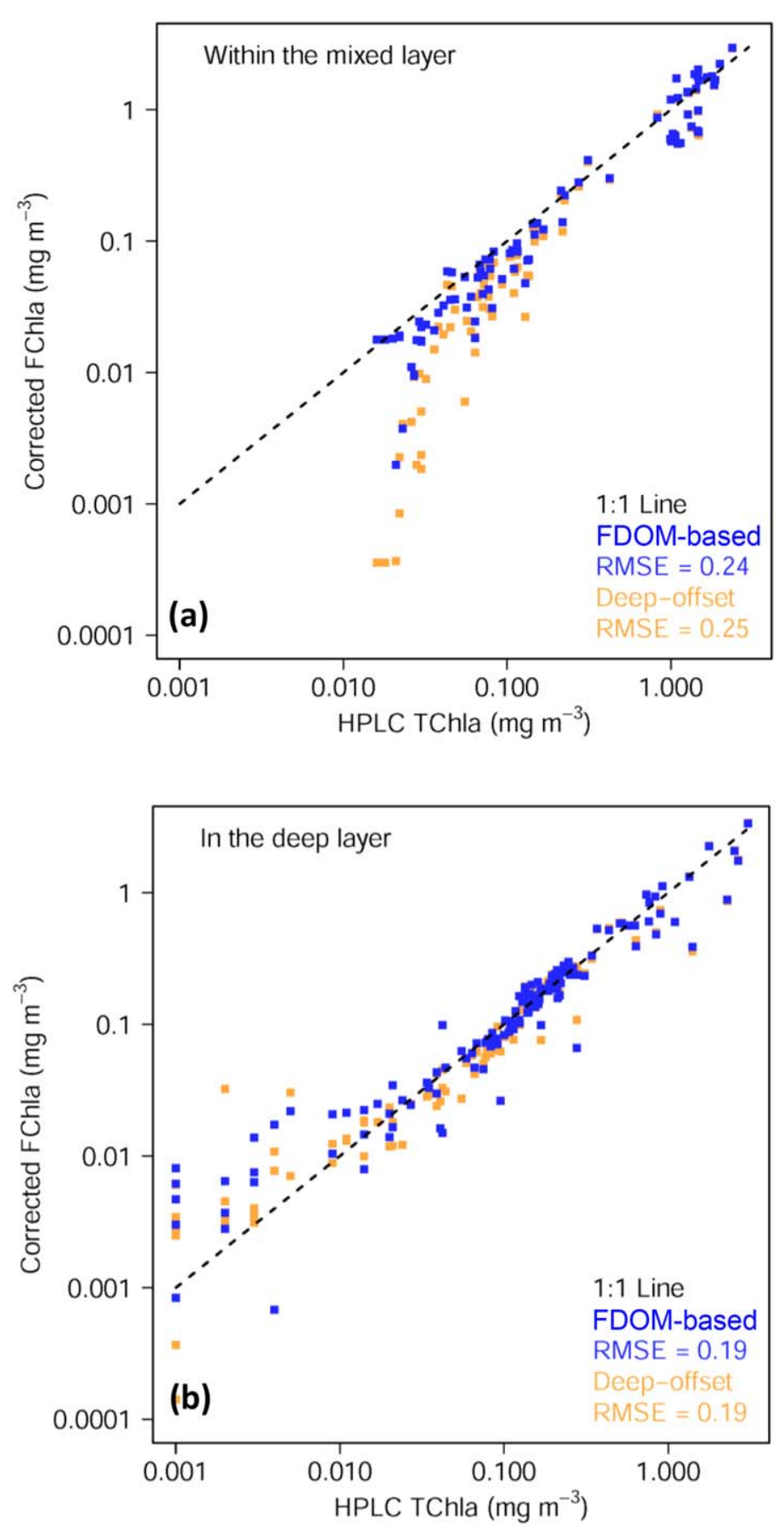

Fig. 5. Scatter plots of the corrected chlorophyll-a concentration by the two methods (FDOM-based method and deep-offset correction) and HPLC TChla for all observations of the BIOSOPE cruise (a) within the mixed layer and (b) in the deep waters (i.e., the depth range used for the linear regression analysis).

correcting the deep non-zero issue of FChla at depth. By contrast, the FDOM-based method allows the retrieval of a continuously decreasing profile with depth, which finally reduces to near zero at $>280 \mathrm{~m}$ (Fig. 4c). Quantitatively speaking, RMSE values are calculated as 0.032 and $0.012 \mathrm{mg}$ $\mathrm{m}^{-3}$ for the deep-offset correction and FDOM-based method, respectively (Fig. 4d).

In what follows we find that the contamination effect of FDOM on FChla is not only significant at depth, but often also near the surface. In surface waters (within the mixed layer), especially in the low-chlorophyll a regime $\left(<0.1 \mathrm{mg} \mathrm{Chla}^{-3}\right)$ of the subtropical gyre, the FDOMbased method allows a better retrieval of Chla concentration than the deep-offset correction as highlighted by Fig. 5a. This is confirmed by results presented in Table 1 where the deep-offset correction retrieves negative FChla for four profiles and values not different from zero for another four. By contrast the FDOM-based correction provides negative values in two cases only. Note that part of the discrepancy that still remains with HPLC data once the FDOM-based correction has been applied likely arise from non-photochemical quenching (NPQ), a phenomena whereby phytoplankton exposed to significant radiance exhibit a decrease in fluorescence per chlorophyll concentration (not addressed in this article, but see Xing et al. 2012). At depth (below the mixed layer) the correction has expectedly less impact than in surface water, yet slight improvements are observed using this correction method (Fig. 5b, see RMSE and $r^{2}$ coefficient).

It should be noted that, not only NPQ, but also other several factors could drive differences between Chla fluorescence and HPLC-determined chlorophyll-a concentration, including changes in community composition, particularly the relative abundance of cyanobacteria vs. eukaryotes, and physiological variation in specific absorption and quantum yield. It means that, it is very difficult to completely and accurately assess the correction method, only based on the matchup between corrected FChla and HPLC Chla. In the current article we are focused on correcting the shape of the FChla profile ignoring the important issue of the uncertainties in absolute calibration of chlorophyll fluorometers (e.g., Cullen, 1982). We are actively working on a manuscript that will address it in general and in particular in the context of profiling floats (Roesler et al., in prep.).

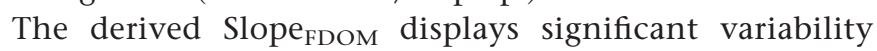
along the BIOSOPE transect (Table 1). It is lowest in the oligotrophic waters of the gyre center, with an average value as only 0.005; in mesotrophic waters associated with the eastern border of the gyre, its averaged value increases up to 0.02 , while in the eutrophic waters associated with the upwelling, Slope $\mathrm{FDOM}_{\mathrm{m}}$ varies around an average value of 0.04 .

\section{Application to Bio-Argo floats data}

Following the above validation, the FDOM-based method is applied to the Bio-Argo dataset. We first determine whether FChla at depth is driven by FDOM by computing their respective gradients with depth. The depth-gradients of FChla and 
Table 1. Comparison between the results of deep-offset correction and FDOM-based method applied to the data of BIOSOPE cruise in the South East Pacific.

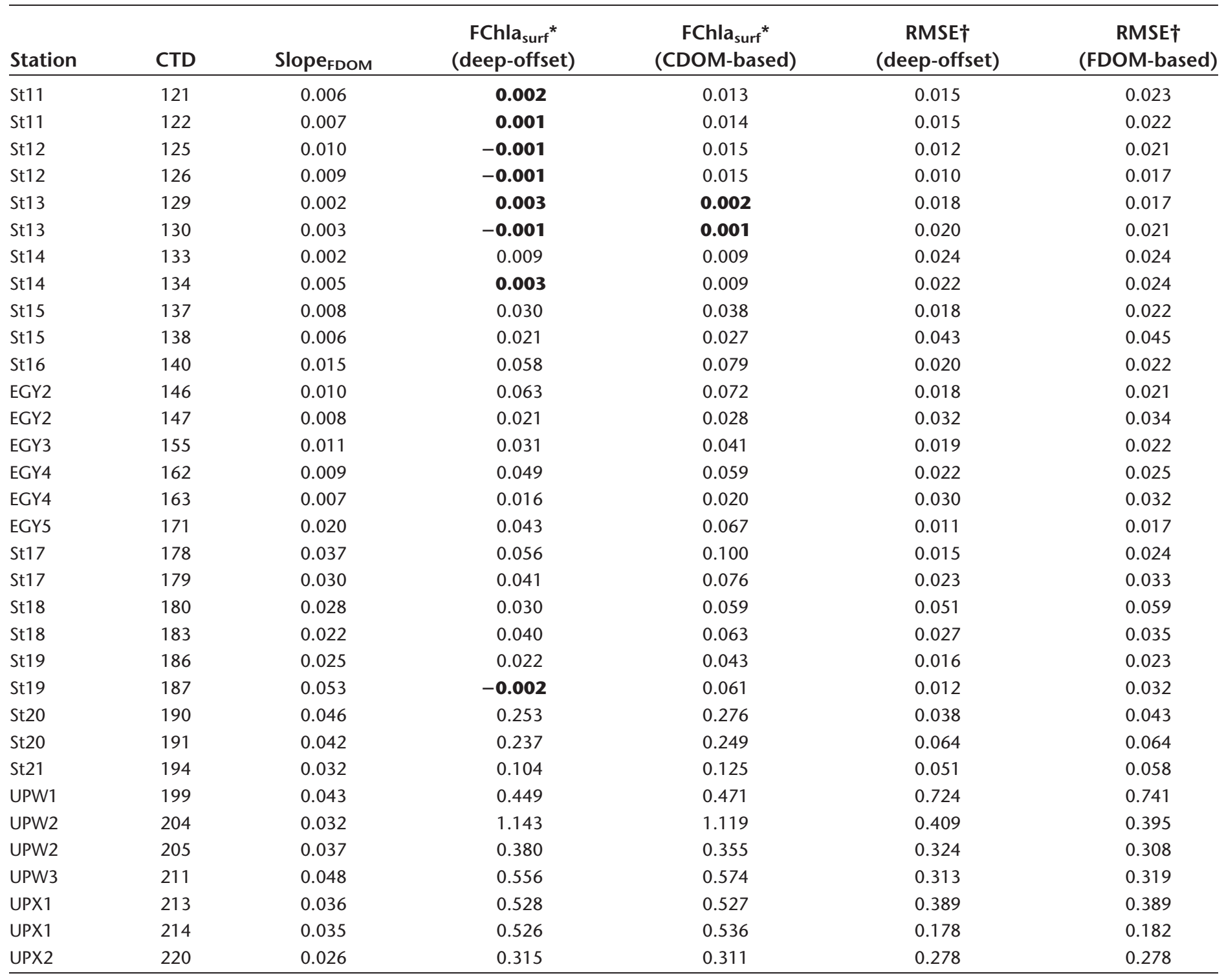

**FChla surface values $\left(<5 \mathrm{~m}\right.$ ) (units $\mathrm{mg} \mathrm{m}^{-3}$ ) corrected by two methods (deep-offset correction and FDOM-based method).

${ }^{\dagger}$ RMSE (Root Mean Square Error) (units $\mathrm{mg} \mathrm{m}^{-3}$ ) between FChla corrected by two methods (deep-offset correction and FDOM-based method) and HPLC TChla for each profile.

FDOM (from the TopDepth [Eq. 6] to $1000 \mathrm{~m}$ ) of all 82 floats (the median value is chosen for each float) are compared in Fig. 6. Among them, the two floats of the Black Sea show the strongest depth-gradients, followed by the subtropical regions. For other regions the depth-gradient values at depth are small, especially in the Mediterranean Sea (Table 2). Overall a good linear relationship is found between the depth-gradients of FChla and FDOM for all floats $\left(r^{2}=0.97\right)$, the determination coefficient becomes 0.49 when the Black Sea is excluded.
A striking example of the application of FDOM-based correction method to a profile acquired in the Black Sea can be observed by comparing Fig. 1b vs. Fig. 7. This profile exhibits an apparent deep minimum around $70 \mathrm{~m}$, and then increases from 70 to $1000 \mathrm{~m}$. FDOM is distributed in a similar way from 70 to $1000 \mathrm{~m}$ (Fig. 1b). After the application of the FDOM-correction the corrected FChla values from 70 to $1000 \mathrm{~m}$ are around zero (Fig. 7b). By contrast, the deepoffset correction method does not remove the red fluorescence in deeper waters. 

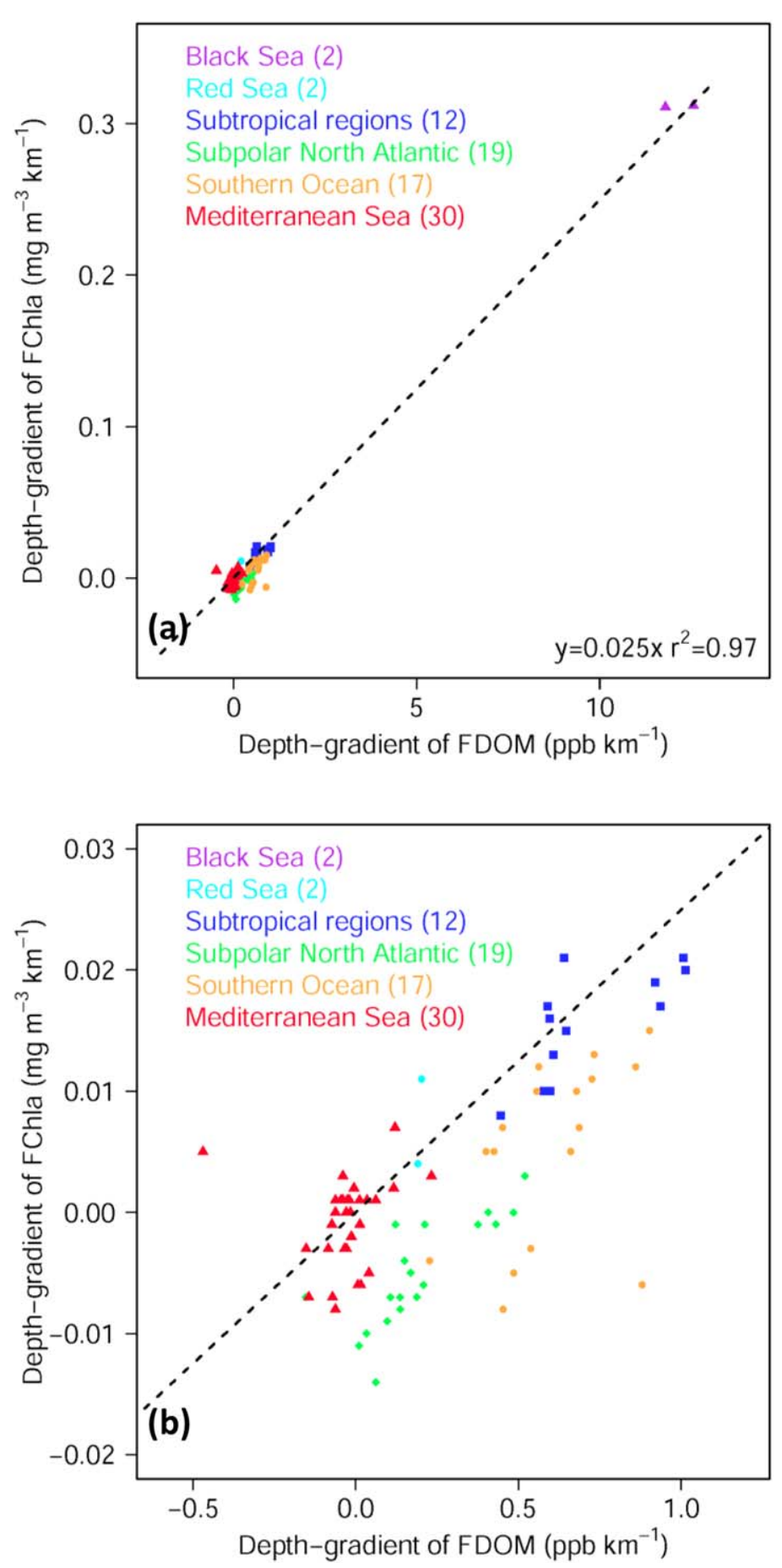

Fig. 6. Scatter plots of the depth-gradients of FChla and depth-gradients of FDOM of all 82 Bio-Argo floats with the black dashed line representing the linearly regressed line $\left(y=0.025 x, r^{2}=0.97\right)$. Each point represents the averaged value of all profiles observed by each float.

\section{Discussion}

\section{Potential source of deep sea red fluorescence}

"Deep sea red fluorescence" signal was first observed with the chlorophyll-a fluorometer in the oxygen minimum zone
(OMZ) of the eastern tropical Pacific where in vivo phytoplankton biomass was expected to be close to zero during the VORTEX experiment (Broenkow et al. 1983; Lewitus and Broenkow 1985). This signal was found to be related to the bacterial activity. In the OMZ of Arabian Sea, Breves et al. (2003) observed a similar phenomenon and found that the deep red florescence had a similar vertical shape to DOM fluorescence. Afterwards, Claustre et al. (2008) noticed that such a deep red fluorescence also appeared in the subtropical South Pacific and it was clearly associated with suboxic conditions. Recently, Röttgers and Koch (2012) reported that, the deep sea red fluorescence was related to heterotrophic bacteria which could be detected in absorption and fluorescence measurement of DOM. Most previous observations were from the tropics and subtropics, and seemed to be related to $\mathrm{OMZ}$ and bacterial activity. Our results exhibit large Slope $_{\text {FDOM }}$ values in the subtropical areas and typical OMZ regions (the Black Sea and Red Sea) (Table 2), suggesting that the main source of deep sea red fluorescence is probably related to heterotrophic bacteria. However, it cannot concluded that the deep sea red fluorescence is emitted by bacteria, as the DOM probably co-varies with microbial concentration (Nelson et al. 1998), especially for the humiclike FDOM (Jørgensen et al. 2011; De La Fuente et al., 2014). On a global scale it has been observed that the humic-like FDOM signal (typical emission wavelengths above $400 \mathrm{~nm}$ ) was significantly correlated with microbial activity, while the amino acid-like DOM fractions (typical emission wavelengths lower $400 \mathrm{~nm}$ ) were linked to newly produced DOM in surface waters (Jørgensen et al. 2011; Nelson and Gauglitz 2016).

Moreover, both in situ and lab experiments identified dissolved and particulate organic matters as able to fluoresce in the red band leading to potential interference in the fluorometry-based retrieval of chlorophyll-a concentration (Herbland 1978; Parker 1981; Marra and Langdon 1993; Proctor and Roesler 2010; Twiss 2011; Goldman et al. 2013; Kring et al. 2014). In this study, the remarkable distinctions of Slope ${ }_{\text {FDOM }}$ between regions (Table 2) indicates that, probably the different colored detrital matter (CDM) or DOM components have distinct fluorescence quantum yields, or that bacteria played a more important role than CDM in the deep sea red fluorescence, or both.

\section{Vertical variations of Slope $\mathrm{FDOM}_{\mathrm{FD}}$}

The new FDOM-based method relies on the assumption

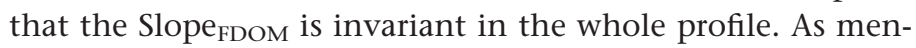

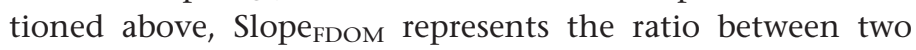
FDOM signals (one measured with the chlorophyll fluorometer, the other with the DOM fluorometer). Given changes in FDOM composition (bacteria, non-algal particles, and/or different CDOM components) and hence its fluorescence characteristics, the conversion coefficient is expected to vary in time and space (including in the vertical). Indeed the 
Table 2. Averaged depth-gradient of FChla (units $\mathrm{mg} \mathrm{m}^{-3} \mathrm{~km}^{-1}$ ), depth-gradient of FDOM (units ppb $\mathrm{km}^{-1}$ ) and Slope $\mathrm{FDOM}$ in different regions of Bio-Argo dataset, including the Black Sea ("BLA"), Red Sea ("RED"), Mediterranean Sea ("MED"), subpolar North Atlantic ("SPNA"), subtropical North Atlantic ("STNA"), subtropical South Atlantic ("STSA"), subtropical South Pacific ("STSP"), and the Atlantic and Indian sectors of the Southern Ocean ("SO").

\begin{tabular}{|c|c|c|c|c|c|}
\hline Region & $\begin{array}{c}\text { Depth-gradient } \\
\text { of FChla }\end{array}$ & $\begin{array}{c}\text { Depth-gradient } \\
\text { of FDOM }\end{array}$ & Slope $_{\text {FDOM }}$ & $\begin{array}{c}\text { Profile } \\
\text { Num }\end{array}$ & $\begin{array}{c}\text { Magnitude of } \\
\text { correction in } \mathrm{ML}^{*}\end{array}$ \\
\hline BLA & 0.312 & 12.29 & $0.025 \pm 0.001$ & 115 & $3.34 \%$ \\
\hline MED & -0.002 & -0.023 & $0.007 \pm 0.013$ & 2642 & $19.10 \%$ \\
\hline SPNA & -0.006 & 0.147 & $0.009 \pm 0.042$ & 2214 & $6.92 \%$ \\
\hline STNA & 0.018 & 0.919 & $0.018 \pm 0.011$ & 375 & $18.40 \%$ \\
\hline STSP & 0.016 & 0.580 & $0.024 \pm 0.009$ & 423 & $39.99 \%$ \\
\hline so & 0.012 & 0.647 & $0.014 \pm 0.033$ & 1738 & $9.73 \%$ \\
\hline
\end{tabular}

Each value represents the averaged values of all profiles observed by several floats in the same region.

*The Magnitude of correction (\%) in the mixed layer signifies the relative difference between the FDOM-based corrected FChla profile and raw FChla profile.
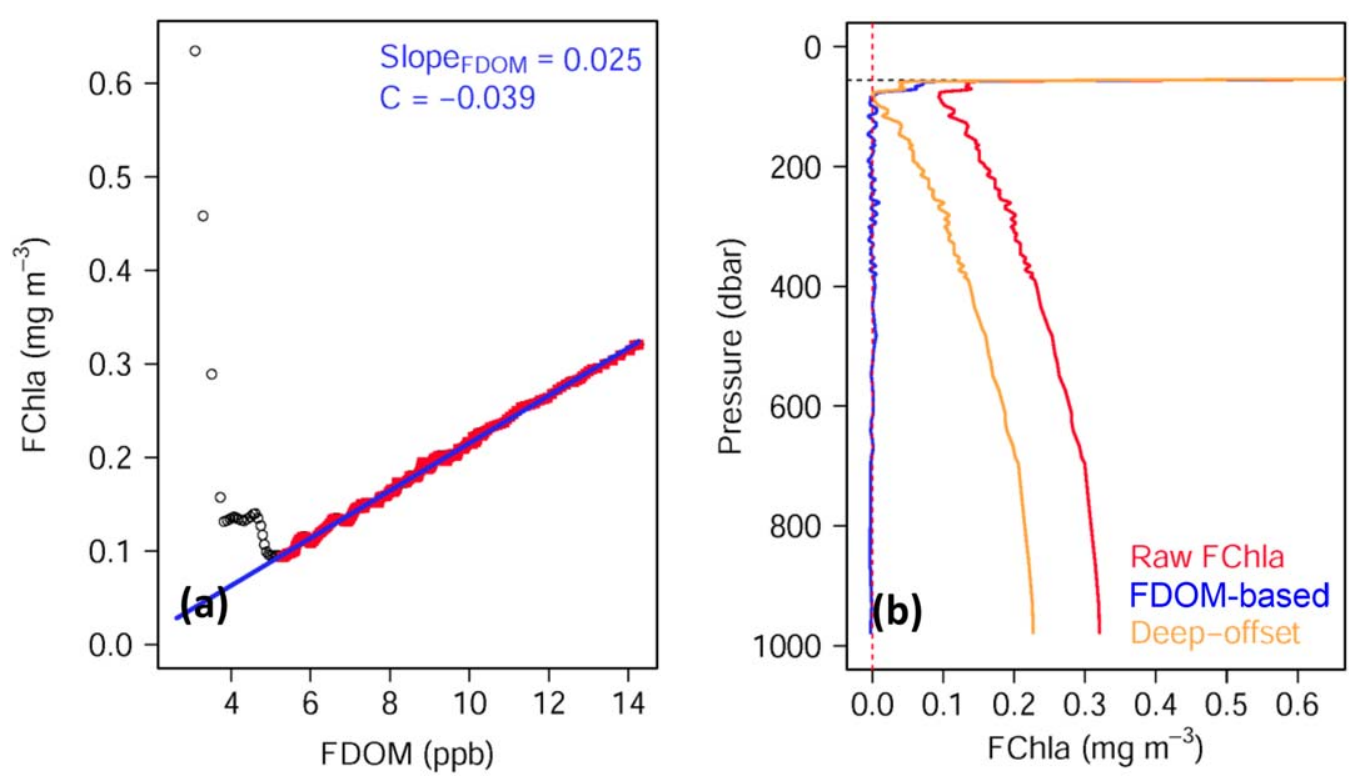

Fig. 7. Example of the FDOM-based method and its comparison with deep-offset correction, for the Black Sea profile presented in Fig. 1b. (a) Scatter plot between FDOM and FChla, with red points represent the points for the linear regression analysis over the depth range from 83.5 to $978.5 \mathrm{~m}$ (b) Vertical profile of FChla corrected by two methods.

derived Slope FDOM $_{\text {varies }}$ with different waters through the BIOSOPE transect (Fig. 3b) and varies between diverse oceanic regions explored with the Bio-Argo dataset (from 0.005 to $0.04)$.

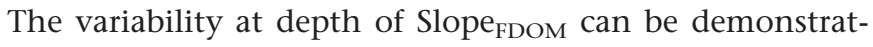
ed from one profile also measured in the eastern border of the South Pacific subtropical gyre (near to the profile displayed in Fig. 1a). For such a profile, although the deep FChla signal appeared related to FDOM (comparing Fig. $8 \mathrm{a}, \mathrm{c})$, some abnormal negative values appears in the corrected FChla profile. This is because both fluorescence signals are not linearly related at depth with some points markedly below the regressed line (Fig. 8b). It is noteworthy that these over-corrected FChla data correspond to very high FDOM. This suggests the observed high FDOM values represent another water mass with high FDOM and different FDOM composition, resulting in change of Slope FDOM $_{\text {in the }}$ vertical. Despite this variability the FDOM-based method provides an improvement when compared to the deep-offset correction (Fig. 8c,d). 
South East Pacific $\left(33.35^{\circ} \mathrm{S} 78.12^{\circ} \mathrm{W}\right)$
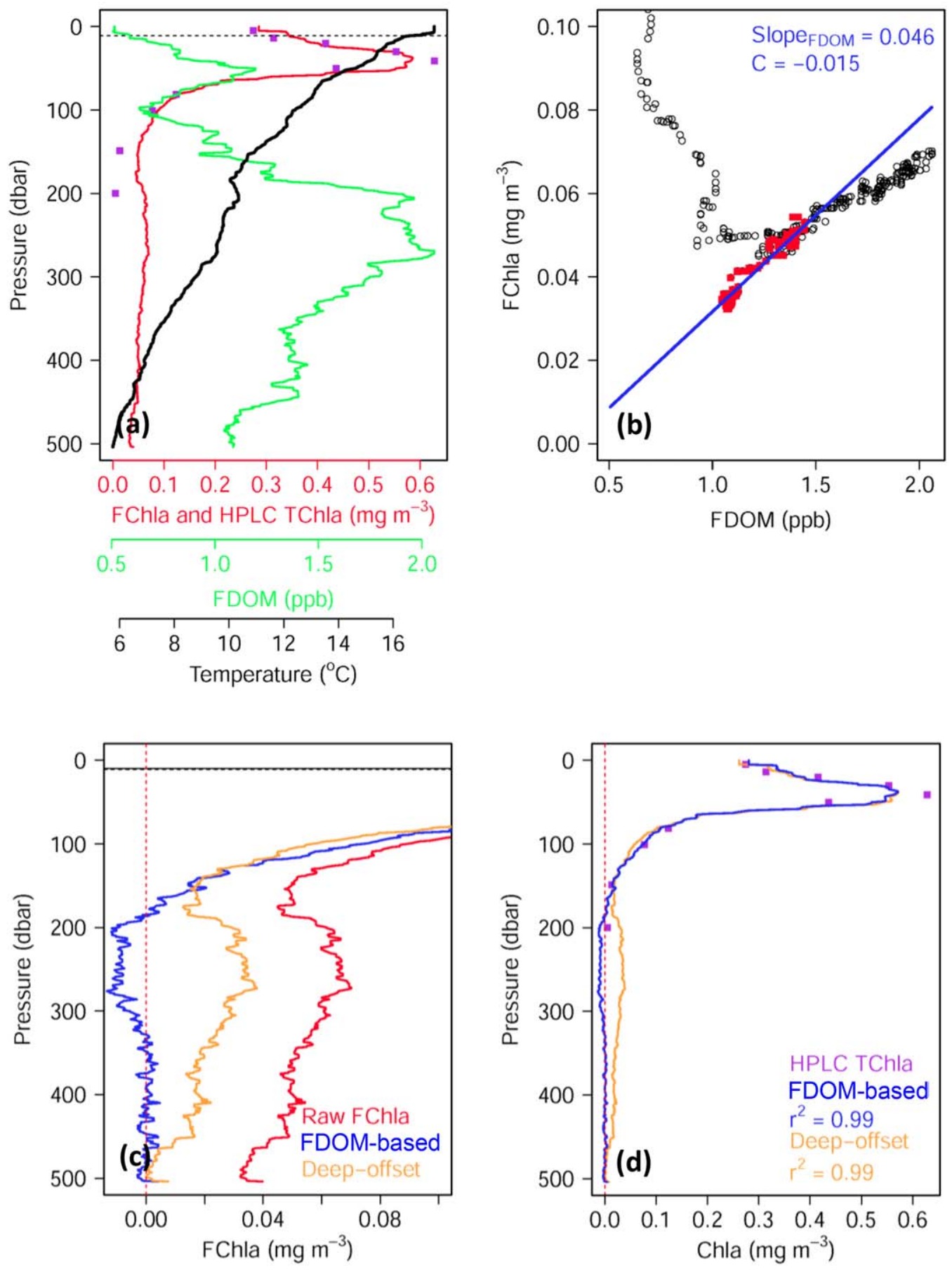

Fig. 8. Example of the FDOM-based method and its comparison with deep-offset correction in the case of a varying FDOM vs. FChla over the depth range for a station in the South East Pacific sampled during the BIOSOPE cruise (station: St20-CTD190, 4 December 2004) (a) vertical profile of FDOM, FChla, and temperature (b) scatter plot between FDOM and FChla, with red points represent the points for the linear regression analysis over the depth range from 400 to $500 \mathrm{~m}$. (c) detail of the dark corrected profiles by two methods at depth (d) Vertical profile of FChla corrected by two methods with HPLC data superimposed. 
Table 3. Averaged RMSE (units $\mathrm{mg} \mathrm{m}^{-3}$ ) of deep-offset correction vs. minimum-offset method, taking the profiles of FDOM-based method as the reference.

\begin{tabular}{lcc}
\hline Region & $\begin{array}{c}\text { RMSE } \\
\text { (deep-offset) }\end{array}$ & $\begin{array}{c}\text { RMSE } \\
\text { (minimum-offset) }\end{array}$ \\
\hline Black Sea & $0.102 \pm 0.016$ & $0.006 \pm 0.009$ \\
Red Sea & $0.008 \pm 0.011$ & $0.003 \pm 0.007$ \\
Mediterranean Sea & $0.004 \pm 0.011$ & $0.005 \pm 0.009$ \\
Subpolar North Atlantic & $0.007 \pm 0.013$ & $0.006 \pm 0.010$ \\
Subtropical North Atlantic & $0.013 \pm 0.014$ & $0.004 \pm 0.014$ \\
Subtropical South Atlantic & $0.010 \pm 0.012$ & $0.003 \pm 0.011$ \\
Subtropical South Pacific & $0.011 \pm 0.004$ & $0.004 \pm 0.001$ \\
Southern Ocean & $0.010 \pm 0.012$ & $0.005 \pm 0.010$ \\
BIOSOPE (St11-St14) & $0.004 \pm 0.006$ & $0.002 \pm 0.001$ \\
BIOSOPE (St15-St19) & $0.007 \pm 0.002$ & $0.004 \pm 0.002$ \\
BIOSOPE (St20-UPX2) & $0.010 \pm 0.003$ & $0.010 \pm 0.003$ \\
\hline
\end{tabular}

Operational real time and delayed mode quality control procedures of Bio-Argo dataset

The increase in FChla with water depth does not occur everywhere (Fig. 6 and Table 2). In many high latitude regions as well as the Mediterranean Sea, FChla does not display this issue. It means that the deep-offset correction method is applicable in these waters. This has implications for real time quality control processing of Bio-Argo FChla data, a fundamental step of the Argo data management system (Wong et al. 2015). In these regions the deep-offset correction could be applied (Schmechtig et al. 2014) in the real time quality control procedure, and the FDOM-based method could be applied in the delayed-mode quality control procedure, examining the depth-gradients of FChla and FDOM to provide a better estimate of chlorophyll fluorometry (if available).

A significant number of Bio-Argo floats, however, measure FChla but no FDOM. For these floats, first the depthgradients of FChla should be examined. If the values are negligible (e.g., $<0.01 \mathrm{mg} \mathrm{m}^{-3} \mathrm{~km}^{-1}$ ), it means the deep-offset correction would be valid for the dark correction. If not, one could apply an alternative method, hereafter called minimum-offset method as follows: First, find the FChla minimum at depth and use it as the value of the Offset; Second, subtract this value from the whole FChla profile (as with the deep-offset correction); Last, assume FChla is zero below the minimum of FChla.

In Table 3, RMSE values for deep-offset correction and minimum-offset method are compared, taking the FDOMbased corrected FChla profiles as the reference. The minimumoffset correction method performs better than the deep-offset correction method. The difference varies according to the region. Since higher depth-gradient of FChla and Slope FDOM mean more remarkable "deep non-zero issue," the error of offset correction at depths reaches its maximum in the Black Sea
( $\left.\sim 0.1 \mathrm{mg} \mathrm{m}^{-3}\right)$, and is also very high in the subtropical gyres $\left(\sim 0.011 \mathrm{mg} \mathrm{m}^{-3}\right)$, while it is the lowest in the Mediterranean Sea and subpolar North Atlantic (corresponding to lowest depth-gradient FChla). By contrast, the minimumoffset method at depths generally has only a low error as $\sim 0.004 \mathrm{mg} \mathrm{m}^{-3}$.

It is noteworthy that the minimum-offset method only resolves the issue of deep red fluorescence to some extent. First, it provides the same profile as the deep-offset correction above the minimum of FChla, thus the very low even negative surface values may appear in some specific regions (e.g., the subtropical waters), as shown and discussed in the Assessment section. Second, it may not work well for some profiles with curved shape, once the minimum of FChla appears around the maximum observation depth (bottom of "curve") as shown in Figs. 1a, 8c. A comparison between deep-offset correction and minimum-offset method for BIOSOPE data is also presented in Table 3. The improvement is obvious in oligotrophic waters (St11-St14), whereas there is almost no change between the two methods in the eutrophic waters (St20-UPX2) because the minimum of FChla generally appears around $500 \mathrm{~m}$.

\section{Comments and recommendations}

Based on previous studies and the observations analyzed here, a novel correction method for in situ chlorophyll fluorometry is proposed to better estimate the shape of FChla, and resolve the "deep non-zero issue" of apparent FChla in some specific regions. Here are some recommendations on processing the chlorophyll fluorescence data:

1. The correction of FChla based on FDOM improves FChla retrieval, especially in regions with high variations of FDOM in deep waters. Thus a DOM fluorometer is recommended to be deployed together with a chlorophyll fluorometer. This is especially critical for the retrieval of accurate FChla in sub-tropical areas where significant FChla and FDOM gradients are recorded at depth.

2. To retrieve more accurately the correction coefficient, Slope $_{\text {FDOM, }}$ it is better to record the FChla and FDOM in a large depth range for linear regression analysis. Thus the maximum observation depth is recommended to be at least as deep as $1000 \mathrm{~m}$.

3. In the case of floats without DOM fluorometer or without valid FDOM measurement, the depth-gradients of FChla could be examined first. If they are negligible $(<0.01 \mathrm{mg}$ $\left.\mathrm{m}^{-3} \mathrm{~km}^{-1}\right)$, the deep-offset correction is still useful. If not, one should consider FChla as zero below its minimum (i.e., the so-called minimum-offset method). Minimum values should be recorded for a range of profiles to obtain the statistic of the minimum, and, assuming the sensor does not drift, use a robust value over the life of the float. 


\section{References}

Blain, S., S. Renaut, X. Xing, H. Claustre, and C. Guinet. 2013. Instrumented elephant seals reveal the seasonality in chlorophyll and light-mixing regime in the ironfertilized Southern Ocean. Geophys. Res. Lett. 40: 63686372. doi:10.1002/2013GL058065

Breves W., R. Heuermann, and R. Reuter. 2003. Enhanced red fluorescence emission in the oxygen minimum zone of the Arabian Sea. Ocean Dyn. 53: 86-97. doi:10.1007/ s10236-003-0026-y

Broenkow, W. W., A. J. Lewitus, M. A. Yarbrough, and R. T. Krenz. 1983. Particle fluorescence and bioluminescence distributions in the eastern tropical Pacific. Nature 302: 329-331. doi:10.1038/302329a0

Boss, E., D. Swift, L. Taylor, P. Brickley, R. Zaneveld, S. Riser, M. J. Perry, and P. G. Strutton. 2008. Observations of pigment and particle distributions in the western North Atlantic from an autonomous float and ocean color satellite. Limnol. Oceanogr. 53: 2112-2122. doi:10.4319/ lo.2008.53.5_part_2.2112

Boss, E., and M. Behrenfeld. 2010. In situ evaluation of the initiation of the North Atlantic phytoplankton bloom. Geophys. Res. Lett. 37: L18603. doi:10.1029/2010GL0 44174

Cetinić, I., G. Toro-Farmer, M. Ragan, C. Oberg, and B. H. Jones. 2009. Calibration procedure for Slocum glider deployed optical instruments. Opt. Express 17: 1542015430. doi:10.1364/OE.17.015420

Claustre, H., A. Sciandra, and D. Vaulot. 2008. Introduction to the special section: Bio-optical and biogeochemical conditions in the South East Pacific in late 2004 - the BIOSOPE program. Biogeosciences 5: 679-691. doi: 10.5194/bg-5-679-2008

Coble, P. G. 1996. Characterization of marine and terrestrial DOM in seawater using excitation-emission matrix spectroscopy. Mar. Chem. 51: 325-346. doi:10.1016/0304-4203(95)00062-3

Coble, P. G. 2007. Marine optical biogeochemistry: The chemistry of ocean color. Chem. Rev. 107: 402-418. doi: $10.1021 / \mathrm{cr} 050350+$

Cullen, J. J. 1982. The deep chlorophyll maximum: Comparing vertical profiles of chlorophyll a. Can. J. Fish. Aquat. Sci. 9: 791-803. doi:10.1139/f82-108

De La Fuente, P., C. Marrasé, A. Canepa, X. Antón ÁlvarezSalgado, M. Gasser, N. M. Fajar, C. Romera-Castillo, and J. L. Pelegrí. 2014. Does a general relationship exist between fluorescent dissolved organic matter and microbial respiration? - the case of the dark equatorial Atlantic Ocean. Deep-Sea Res. I 89: 44-55. doi:10.1016/j.dsr.2014.03.007

Falkowski, P., and D. A. Kiefer. 1985. Chlorophyll a fluorescence in phytoplankton: Relationship to photosynthesis and biomass. J. Plankton Res. 7: 715-731. doi:10.1093/plankt/7.5.715

Geider, R. J., H. L. MacIntyre, and T. Kana. 1998. A dynamic regulatory model of phytoplanktonic acclimation to light, nutrients, and temperature. Limnol. Oceanogr. 43: 679694. doi:10.4319/1o.1998.43.4.0679

Goldman, E. A., E. M. Smith, and T. L. Richardson. 2013. Estimation of chromophoric dissolved organic matter (CDOM) and photosynthetic activity of estuarine phytoplankton using a multiple-fixed-wavelength spectral fluorometer. Water Res. 47: 1616-1630. doi:10.1016/j.watres. 2012.12.023

Guinet, C., and others. 2013. Calibration procedures and first data set of Southern Ocean chlorophyll-a profiles collected by elephant seal equipped with a newly developed CTD-fluorescence tags. Earth Syst. Sci. Data 5: 15-29. doi:10.5194/essd-5-15-2013

Herbland. A. 1978. The soluble fluorescence in the open sea: Distribution and ecological significance in the Equatorial Atlantic Ocean. J Exp. Mar. Biol. Ecol. 32: 275-284.

Jørgensen, L., C. A. Stedmon, T. Kragh, S. Markager, M. Middelboe, and M. Søndergaard. 2011. Global trends in the fluorescence characteristics and distribution of marine dissolved organic matter. Mar. Chem. 126: 139-148. doi: 10.1016/j.marchem.2011.05.002

Kinkade, C. S., J. Marra, T. D. Dickey, C. Langdon, D. E. Sigurdson, and R. Weller. 1999. Diel bio-optical variability in the Arabian Sea as observed from moored sensors. Deep-Sea Res. II 45: 1813-1832. doi:10.1016/S0967-0645(99)00045-4

Kring, S. A., S. E. Figary, G. L. Boyer, S. B. Watson, and M. R. Twiss. 2014. Rapid in situ measures of phytoplankton communities using the bbe FluoroProbe: Evaluation of spectral calibration, instrument intercompatibility, and performance range. Can. J. Fish. Aquat. Sci. 71: 10871095. doi:10.1139/cjfas-2013-0599

Lewitus, A. J., and W. W. Broenkow. 1985. Intermediate depth pigment maxima in oxygen minimum zones. DeepSea Res. 32: 1101-1115. doi:10.1016/0198-0149(85)90065-2

Lorenzen, C. 1966. A method for the continuous measurement of in vivo chlorophyll concentration. Deep-Sea Res. 13: 223-227. doi:10.1016/0011-7471(66)91102-8

MacIntyre, H. L., E. Lawrenz, and T. L. Richardson. 2011. Taxonomic discrimination of phytoplankton by spectral fluorescence, p. 129-169. In D. J. Suggett, O. Prasil, and M. A. Borowitzka [eds.], Chlorophyll a fluorescence measurements in aquatic sciences: Methods and applications. Springer.

Marra, J. and C. Langdon. 1993. An evaluation of an in situ fluorometer for the estimation of chlorophyll a. Technical Report LDEO-93-1. Lamont-Doherty Earth Observatory, Palisades, $41 \mathrm{p}$.

Mignot, A., H. Claustre, J. Uitz, A. Poteau, F. D'Ortenzio, and X. Xing. 2014. Understanding the seasonal dynamics of phytoplankton biomass and DCM in oligotrophic environments: A Bio-Argo float investigation. Global Biogeochem. Cycles 28: 856-876. doi:10.1002/2013GB004781

Monterey, G., and S. Levitus. 1997. Seasonal variability of mixed layer depth for the world ocean. NOAA Atlas NESDIS 14, 100p. Natl. Oceanic and Atmos. Admin. 
Mroczka, J. 1988. Temperature stabilization of light-emitting diode radiation. J. Phys. E, Sci. Instrum. 21: 306-309. doi: 10.1088/0022-3735/21/3/014

Nelson, N. B., D. A. Siegel, and A. F. Michaels. 1998. Seasonal dynamics of colored dissolved material in the Sargasso Sea. Deep-Sea Res. I 45: 931-957. doi:10.1016/S09670637(97)00106-4

Nelson, N. B., and J. M. Gauglitz. 2016. Optical signatures of dissolved organic matter transformation in the global ocean. Front. Mar. Sci. 2: 118. doi:10.3389/fmars.2015.00118

Niewiadomska, K., H. Claustre, L. Prieur, and F. D'Ortenzio. 2008. Submesoscale physical-biogeochemical coupling across the Ligurian current (northwestern Mediterranean) using a bio-optical glider. Limnol. Oceanogr. 53: 22102225. doi:10.4319/1o.2008.53.5_part_2.2210

Organelli, E., and others. 2016. A novel near real-time qualitycontrol procedure for radiometric profiles measured by BioArgo floats: Protocols and performances. J. Atmos. Oceanic Technol. 33: 937-951. doi:10.1175/JTECH-D-15-0193.1

Parker, R. R. 1981. A note on the so-called "soluble fluorescence" of chlorophyll a in natural waters. Deep-Sea Res. A 28: 1231-1235. doi:10.1016/0198-0149(81)90059-5

Pettigrew, N. R., and C. S. Roesler. 2005. Implementing the Gulf of Maine Ocean Observing System (GoMOOS). IEEE proceedings of Oceans '05 (Europe), Brest France, p. 1234-1241.

Platt, T. 1972. Local phytoplankton abundance and turbulence. Deep-Sea Res. 19: 183-187. doi:10.1016/00117471(72)90029-0

Proctor, C. W., and C. S. Roesler. 2010. New insights on obtaining phytoplankton concentration and composition from in situ multispectral Chlorophyll fluorescence. Limnol. Oceanogr. Methods 8: 695-708. doi:10.4319/lom.2010.8.695

Ras, J., J. Uitz, and H. Claustre. 2008. Spatial variability of phytoplankton pigment distributions in the Subtropical South Pacific Ocean: Comparison between in situ and modelled data. Biogeosciences 5: 353-369. doi:10.5194/ bg-5-353-2008

Röttgers, R., and B. P. Koch. 2012. Spectroscopic detection of a ubiquitous dissolved pigment degradation product in subsurface waters of the global ocean. Biogeosciences 9: 2585-2596. doi:10.5194/bg-9-2585-2012

Sackmann, B. S., M. J. Perry, and C. C. Eriksen. 2008. Seaglider observations of variability in daytime fluorescence quenching of chlorophyll-a in Northeastern Pacific coastal waters, Biogeosci. Discuss. 5: 2839-2865. doi:10.5194/bgd5-2839-2008

Schmechtig C., H. Claustre, A. Poteau, and F. D'Ortenzio. 2014. Bio-Argo quality control manual for the ChlorophyllA concentration, Version 1.0, 16 p. doi:10.13155/35385

Sullivan, J., M. Twardowski, J. Zaneveld, and C. Moore. 2013. Measuring optical backscattering in water, p. 189-
224. In A. A. Kokhanovsky [eds.], Light Scattering Reviews 7: Radiative Transfer and Optical Properties of Atmosphere and Underlying Surface. Springer.

Twiss, M. R. 2011. Variations in chromophoric dissolved organic matter and its influence on the use of pigmentspecific fluorimeters in the Great Lakes. J. Great Lakes Res. 37:124-131. doi:10.1016/j.jglr.2010.11.011

Vodacek, A., N. V. Blough, M. D. DeGrandpre, E. T. Peltzer, and R. K. Nelson. 1997. Seasonal variation of CDOM and DOC in the Middle Atlantic Bight: Terrestrial inputs and photooxidation. Limnol. Oceanogr. 42: 674-686. doi: 10.4319/lo.1997.42.4.0674

Wong, A., R. Keeley, T. Carval, and the Argo Data Management Team. 2015. Argo quality control manual for CTD and trajectory data. Version 3.0, 56 p. doi:10.13155/33951

Xing, X., A. Morel, H. Claustre, D. Antoine, F. D'Ortenzio, A. Poteau, and A. Mignot. 2011. Combined processing and mutual interpretation of radiometry and fluorimetry from autonomous profiling Bio-Argo Floats: Chlorophyll a retrieval. J. Geophys. Res. 116: C06020. doi:10.1029/2010JC006899

Xing, X., H. Claustre, S. Blain, F. D'Ortenzio, D. Antoine, J. Ras, and C. Guinet. 2012. Quenching correction for in vivo chlorophyll fluorescence acquired by autonomous platforms: A case study with instrumented elephant seals in the Kerguelen region (Southern Ocean). Limnol. Oceanogr. Methods 10: 483-495. doi:10.4319/lom.2012.10.483

Xing, X., H. Claustre, J. Uitz, A. Mignot, A. Poteau, and H. Wang. 2014. Seasonal variations of bio-optical properties and their interrelationships observed by Bio-Argo floats in the subpolar North Atlantic. J. Geophys. Res. Oceans 119: 7372-7388. doi:10.1002/2014JC010189

\section{Acknowledgments}

This article is a contribution to the Remotely Sensed Biogeochemical Cycles in the Ocean (remOcean) project, funded by the European Research Council (grant agreement 246777), to the ATLANTOS EU project (grant agreement 2014-633211) funded by H2020 program, to the French Bio-Argo project funded by CNES-TOSCA, to the French "Equipement d'avenir" NAOS project (ANR J11R107-F), to the NASA OBB program supporting the integration of optical sensors on SOCCOM floats (NNX14AP49G), to the Project of State Key Laboratory of Satellite Ocean Environment Dynamics, Second Institute of Oceanography (SOEDZZ1601), and to the National Natural Science Foundation of China (41476159). We thank two anonymous reviewers for helping us significantly improve an earlier version of this manuscript.

\section{Conflict of Interest}

None declared.

Submitted 25 April 2016

Revised 04 August 2016

Accepted 12 September 2016

Associate editor: Tammi Richardson 